I am glad that Dr. Beattie acknowledges that he can not guarantee a cure of tuberculosis in any case. We had surmised that the Doctor feit equal to the task of euring many if not most cases of tuberculosis he might encounter.

I must thank Dr. Beattie for the statement that " his own experience" will not lead him to "say that oxytuberculin will cure a single case of tuberculosis." $\mathrm{He}$ coincides with the majority of the medical profession in that regard. There is never a contra-indication toward applying any remedy which will relieve distressing symptoms. I fail to understand what he calls a "specific treatment." I think no remedy can properly be classed as a specific until it will positively and perma nently cure a fair per cent. of a particular sort of cases.

Yours respectfully,

E. H. Sмiтh, M.D.

\section{Grand River Valley Medical Association.}

Holland, Mich., March 28, 1898.

To the Editor:-On page 739 of the Journal, March 26, 1898, under the head of "Post-Graduate Lectures at Home," it is claimed Eastern medical societies have adopted a new plan by which they increase their membership and interest in the meetings. The Grand River Valley Medical Society of Michigan adopted this plan in 1894 when at their annual meeting Prof. J. H. Etheridge was invited to be with us and read a very instructive paper; since which time we have had such men as Professors Dock and McClintock of Ann Arbor, Professors Graves, Green, Boise and Griswold of Grand Rapids. We find our meetings are made very instructive by this plan and will continue it as long as we can procure volunteers for their expenses and entertainment. Will some Chicago men volunteer for our May and August meetings, which occur on the second Tuesdays of those months?

\section{B. B. Godfrex, M.D., Sec.}

\section{Why Not the House Cat? \\ Lansdowne, $\mathrm{PA}_{\mathrm{A}}$, March 2, 1898.}

To the Editor:-I have been interested in the letters regarding the castration of squirrels, in the March 5 issue of your excellent JournaL, and it occurs to me to suggest that some learned member of the profession set himself to the bringing out of some scheme whereby the squirrels might be led to teach their progeny-limiting process to the common house cat! In the interest of peace and quietness and sweet refreshing sleep, such an happy "artiflcial cut-off" as Saxe says, is needed. Fame and fortune await him who will bring to pass this step toward Heaven. Sincerely, J. M. IAAurison, M.D.

\section{ASSOCIATION NEWS.}

Section on State Medicine.-The following additional papers (vide Journal, March 26, p. 743), for this Section:

The Importance of the Immediate Sterilizing of Foods and Drinks before their Ingestion, by Augustus P. Clarke, Cambridge, Mass. ; Henry D. Holton, Brattleboro, Vt., will open discussion.

Relation of the Courts of Lunacy Law or Insanity Before the Law, by Charles H. Hughes, St. Louis, Mo.; discussed by William P. Munn, Denver, and T. D. Crothers, Hartford, Conn. The Milk Supplies of Cities, is the Public Entitled to Receive Better Service? by Henry O. Marcy, Boston, Mass. ; discussed by Henry L. Coit, Newark, N. J.

Some of the Duties of Health Boards, by Henry D. Holton,

Brattleboro, Vt. ; discussed by Charles H. Shepard, Brooklyn.

Alcoholic Stimulation or Irrigation, Which? Including their Uses and the most Efficient means to Obtain their Effects, by W. Van R. Blighton, Buffalo, N. Y.; discussion opened by J. H. Kellogg. Battle Creek, Mich, ; Charles H. Hughes, St. Louis ; T. D. Crothers, Hartford, Conn.; A ugustus P. Clarke, Cambridge, Mass.

The following have promised papers but subjects have not yet been received: Benjamin Lee, Philadelphia ; H. N. Avery,
Minneapolis, Minn.; Lewis D. Mason, Brooklyn; Thos. F. Harrington, Lowell, Mass. ; Elmer Lee, New York City.

Section on Cutaneous Medicine and Surgery.-The Section on Cutaneous Medicine and Surgery (and this includes syphilology) promises to be a useful and interesting meeting. The chairman of the Section, Dr. A. W. Brayton of Indianapolis, has received the following titles of papers.

Treatment of Pigmentary Diseases of the Skin, by Dr. John V. Shoemaker, Philadelphia, the Chairman of the Section on Materia Medica and Therapeutics. Dr. Shoemaker will also hold a clinic on some cases of cutaneous diseases which will be collected by Dr. J. M. Blaine of Denver, the local Chairman of the Section.

The Causes of Sycosis, by Alfred E. Regensburger, San Francisco; Two Cases of Marked Iodin Intoxication with Treatment, by A. H. Ohmann-Dumesnil, St. Louis.

Dr. Wm. S. Gottheil, New York, will read two papers illustrated by casts and photographs.

The Causes of Baldness, by J. M. Blaine, Denver.

Leukemia Cutis, by Wm. Gilbert Hay, San Francisco.

Tuberculosis of the Skin, by A. W. Brayton, Indianapolis.

Syphilis and its Relation to Consumption, by Lincoln Mussey, Denver.

Dr. Wm. H. Davis of Denver, has promised a paper, and papers are expected from Drs. Wm. T. Corlett, Cleveland; T. C. Gilchrist, Johns Hopkins, Baltimore, and Robert Hessler of the Central Hospital for Insane Indianapolis, on "The Effect of Thyroid Medication on the Diseases of the Skin," and a paper from Dr. L. D. Bulkley, New York.

Dr. Wm. T. Corlett writes the Chairman of the Section that he has visited Hot Springs and there will be several attendants on the Section with papers from that locality.

The Section will hold its session in the parlor of Unity Church in the same building with the Section on Materia Medica, and but one short block from the headquarters of the Association, the Brown Hotel.

All additional titles of papers should be sent at once to the Chairman of the Section or to the Secretary, Dr. T. C. Gilchrist, Baltimore, in order that they may appear on the permanent and preliminary programs and announcements.

\section{SOCIETY NEWS.}

Florida Association of Railway Surgeons.-The annual meeting of the Florida State Association of Railway Surgeons will be held at Jacksonville, Fla., Monday, April 25, 1898, at 10:30 o'clock, A.M. J. Harrison Hodges, M.D., Gainsville, Fla., President.

South Carolina Medical Association.-The forty-seventh annual meeting of the South Carolina Medical Association will be held at Harris Lithia Springs, April 13 and 14, 1898. Titles of papers should be sent to the Secretary, who also desires members expecting to attend the Denver meeting of the AMErican Medical Association to advise him. E. F. Parker, M.D., Corresponding Secretary, Charleston, S. C.

Ohio State Medical Society.-At the next annual meeting of the Ohio State Medical Society, Dr. Senn will deliver the address in surgery; Dr. Hare has promised to deliver the address in medicine and a number of the ablest practitioners in Ohio have prepared papers. Matters of interest to the whole profession in the way of medical legislation, will be presented by the State Board of Registration. The headquarters for the Society will be at the Great Southern Hotel in Columbus. The date of the meeting is May 4, 5 and 6, 1898.

Kansas Medical Society.-The thirty-second annual meeting of the Kansas Medical Society will be held in Topeka, Kansas, May 4.5 and 6, 1898. According to resolutions adopted last year, committees from the three State societies, Regulars, 